\title{
环渤海地区城市居住环境满意度评价 及影响因素分析
}

\author{
党云晓 ${ }^{1,2,3}$, 余建辉 $12^{*}$, 张文忠 ${ }^{1,2}$, 李业锦 ${ }^{4}$, 谌 网 $^{5}$, 湛东升 ${ }^{1,2}$ \\ (1. 中国科学院区域可持续发展分析与模拟重点实验室, 北京 $100101 ; 2$. 中国科学院地理科学与资源研究所, \\ 北京 $100101 ; 3$. 中国科学院大学, 北京 $100049 ; 4$. 首都师范大学资源环境与旅游学院,北京 100048 ; \\ 5. 北京联合大学应用文理学院,北京 100191)
}

\begin{abstract}
摘 要: 以环渤海地区为案例区, 综合运用多层线性模型、GIS 空间分析和多元线性回归分析模型, 基于居民主观感 受数据, 对研究区域内 43 个城市的居住环境进行评价, 并探讨城市客观特征对主观评价结果的影响。研究表明: (1)环渤海地区城市之间的居住环境评价差别明显, 辽宁省城市的评价结果整体较优, 河北省城市的评价结果整体 较差; (2)环境健康性是居住环境评价得分较低城市的共同短板; (3)城市规模、人口密度、经济发展水平与居住环境 的满意度均呈负相关, 中小城市的居住环境满意度普遍高于大城市, 临海城市的居民对所在城市的满意度评价更 高; (4)在城市居住环境的可提升要素中,治理雾霍是当前最迫切的任务。
\end{abstract}

关 键 词: 居住环境; 满意度评价; 影响因素; 环渤海地区

\section{1 引言}

过去 30 年, 中国的城市化以世界罕见的速度推 进,城市化率从 1978 年的 $17.92 \%$ 增长到 2014 年的 $54.77 \%$,实现了由农村社会向城市社会过渡的历史 性转变。然而,高速度的城市化在推动社会经济发 展的同时,也存在着重速度与轻质量的“冒进式”现 象(姚士谋等, 2011; 湛东升等, 2015), 暴露出越来越 多的城市问题,例如环境污染、交通拥堵、绿色空间 紧缺等一系列居住环境问题(张文忠等, 2013), 不仅 影响城市居民生活品质的提升, 也严重违背了国家 新型城镇化建设等方针(党云晓等, 2014)。城市化 率超过 $50 \%$ 以后, 城镇化的发展重点不再是速度而 是质量。中国未来城镇化的发展目标是要全力解 决“城市病”问题, 营造和谐宜居的城市生活环境, 不仅要保证城市公共服务水平完善提升, 同时要求
城市生态环境得到明显改善, 自然与文化得到有效 保护。与此同时,随着社会文明的进步与居民经济 收人的增加, 中国居民也开始重视自身的居住环境 品质。在新型城镇化深人实施的“十三五”时期,城 市居住环境成为政府、公众与学术界关注的共同焦 点,研究城市居住环境对于推进新型城镇化及解决 新时期的城市居住环境问题具有非常重要的现实 意义。

居住环境(residential environment)通常指围绕 居住和生活空间的各种环境的总和,包括自然条 件、各种设施条件和地区社会环境等 (Asami, 2001)。一些规划学者认为,居住环境包括三个独 立的维度: 住宅, 居住社区的实体空间结构, 以及代 表社会维度的邻里(Talen, 2006)。居住环境的研究 内容与人居环境相似,但在研究尺度和研究范围上 有所区别, 人居环境通常从全球、区域、城市、社区、

收稿日期: 2015-07; 修订日期: 2015-10。

基金项目: 国家自然科学基金项目 (41230632,41201169) [Foundation: National Natural Science Foundation of China, No 41230632, No.41201169]。

作者简介:党云晓(1987-),女,河南济源人,博士研究生,主要研究方向为城市问题与区域发展,Email: dangyx.09s@igsnrr.ac.cn。 通讯作者:余建辉(1983-) , 男, 甘肃张掖人 助理研究员, 主要从事城市和区域发展研究,Email: yujh@igsnrr.ac.cn。 
建筑五个层次进行研究(吴良镛, 2001), 而居住环境 的研究尺度通常是一个独立的城市或城市内部的 街道、社区和建筑层面, 研究范围也集中在城市的 物质和社会环境等方面。居住环境理念从早期只 关注建筑、街道等物质环境, 随着人本主义兴起, 开 始更加注重人的尺度和人的需要, 强调社会环境的 重要性(张文忠等, 2015)。同时,对于不同的研究尺 度, 居住环境研究内容的关注点也有所不同。例如 在城市尺度, 居住环境研究关注内容为自然生态环 境(Ullman, 1954; Roback, 1982; Glaeser et al, 2001)、 公共服务设施的配置(Glaeser et al, 2006)、社会文化 氛围与历史传承(Clos, 2011; 谌丽等, 2012)等; 而在 社区尺度, 关注的是社区公共空间、建筑密度、社区 级服务设施、邻里交往等(谌丽等, 2008; 李业锦, 2009); 在建筑尺度, 则关注户型、住房面积、家庭关 系等(Mohit et al, 2010)内容。

关于居住环境的评价研究至少包括以下两大 内容: 一是对居住环境的客观实体的评价, 包括对 居住环境影响因素分析、演变机制和集成模拟研 究。采用的评价指标体系主要包括居住硬环境的 构成要素和软环境的构成要素各自所囊括的具体 指标, 指标可分为刻画状态、反映趋势、衡量导向三 类(张文忠等, 2013)。目前国内研究的热点城市有 大连、北京、广州、上海等主要的大城市(李王鸣等, 1999; 李雪铭等, 2004), 以及个别中小城市, 如丹 东、衡阳等(李雪铭等, 2008; 胡最等, 2011)。国外研 究热点主要是全球化的城市或大都市区, 评价指标 体系通常涵盖城市居住环境要素中的教育与医疗 设施的数量及质量、自然环境、交通条件、住房、就 业、社会治安、文化与政治等(Beeson, 1991; 浅见泰 司, 2006; Savageau, 2007)。有关居住环境的演变研 究集中对于比分析不同时刻的居住环境状态, 抑或 是不同城市间同一时刻的居住环境对比研究(张文 忠等, 2013), 综合集成研究则主要探索集成途径与 模拟预测工具(Asami, 2001; Torrens, 2006)。二是 对居住环境主观认知的评价。居住环境是城市居 民日常生活高度关注的问题, 从居民自身出发, 分 析居民对构成居住环境的设施、环境、文化、服务内 容等的心理认知, 对居住环境建设具有重要的指导 意义(张文忠等, 2006)。

从已有研究来看, 虽然基于主观评价的居住环 境研究越来越多, 但这些研究主要是城市内部的小 尺度单元, 例如街道和社区尺度, 受数据搜集等限
制,鲜见基于城市尺度的居住环境主观评价的研 究。基于此, 本文将研究的侧重点放在中国大区域 内部城市尺度的居住环境差异。与以往基于客观 数据的研究相比, 基于居民主观评价的研究更能体 现“以人为本”的城市发展理念。居住环境为人服 务, 其质量的优劣最终还是要由人的主观感受来判 定, 而且以主观感受衡量的居住环境质量也是检验 城市规划与建设质量的有效手段,为城市更新改造 提供更为人性化的意见。

本文采用大规模问卷调研数据, 以环渤海地区 43 个地级市为例, 基于居民的主观评价, 首先分析 城市居住环境评价的整体差异, 然后结合客观数 据, 进一步分析城市的客观特征如何影响主观评价 结果。希望通过本文能初步了解环渤海地区的居 住环境特征, 并为今后研究更大尺度的居住环境差 异及形成机制提供基础。

\section{2 理论框架}

城市尺度的居住环境差别形成机制主要从以 下两个方面解析(图 1): 首先是自然本底的差别, 位 于不同地区的城市其气候、地形、地质及生态条件 表现出不同的特征,由此显示居住环境的差异。例 如, 在降水和光照充足、气温适宜、地质结构稳定、 邻近海洋、生物多样性丰富且地形条件有利于污染 气体扩散的地区, 居住环境的适宜性明显优于其他 地区。其次是人为因素的作用, 又可细分为社会文 化、城市发展和环境破坏 3 个原因。社会文化因素

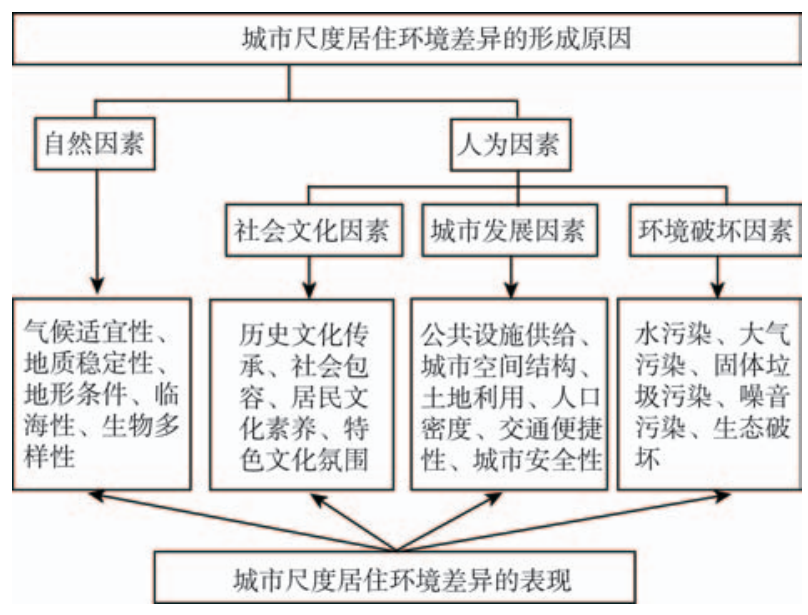

图 1 城市尺度居住环境差异的形成原因及表现形式

Fig.1 Causes and manifestation of living environment heterogeneity at city level 
引起的居住环境差异表现在城市对历史文化的传 承、特色文化氛围、社会包容性和居民的文化素质 方面, 浓郁的历史文化氛围及良好的居民素养均对 城市高品质的生活环境起到正面的影响; 城市发展 因素对居住环境的影响表现在城市公共服务设施 的供给、城市空间结构、发展密度、交通便捷性和城 市安全性方面,这些因素同样是衡量一个城市健康 发展的重要指标; 健康的城市不仅能够通过高效的 土地利用方式组织人口和产业活动, 又能为居民提 供便捷丰富的公共服务; 环境破坏因素表现在城市 的生产和生活活动对环境的破坏, 以牺牲环境为代 价的人类活动必将降低居住环境的品质, 甚至危及 居民的生存安全。

以上是客观存在的居住环境差异, 如果将客观 居住环境的差别映射到居民的主观感受上, 进一步 表现为居民对其所居城市居住环境主观评价的不 一致。本文便是基于居民主观感受来评价居住环 境的差别, 并分析这种差异受到的城市客观特性的 影响。

\section{3 数据与方法}

\section{1 数据说明}

本文选择环渤海地区所有地级市为研究范围, 主要是基于以下几个方面的考虑: (1)环渤海地区是 中国近 30 年来城镇化发展最快的地区之一, 也是城 市发展中暴露问题最集中的地区之一, 可以说这个 地区是中国城市化地区的一个缩影, 研究该区域的 城市居住环境差异及其影响因素在全国范围内具 有一定的代表性。(2)环渤海地区城市类型丰富多 样, 城市因自然本底条件、社会经济发展水平、人文 环境和区域功能定位各异, 多样的城市类型为本文 分析居住环境差异提供了良好的先决条件。需要 特别补充说明的一点是, 本项研究将北京市排除在 外, 这是因为: 一是在整个环渤海地区没有一个城 市可以与北京市相当, 北京市的城市规模、经济发 展水平等超越其他城市非常明显, 这可能会导致北 京市成为研究样本中的 “异常值”; 二是北京市是全 国的政治中心, 国家给予的政策倾斜远远多于其他 城市, 这会造成人为因素的作用明显高于其他城 市; 三是用于本次的调研数据仅涉及其他 43 个地级
市,北京市缺少同一时段的主观数据。

本文中的城市居住环境主观评价得分数据来 源于宜居城市课题组于 2014 年 11 月至 2015 年 2 月 在环渤海三省(河北省、山东省、辽宁省)一市 (天津 市)地区进行的“环渤海城市人居环境评价抽样调 查问卷”。调研问卷直接调查和了解环渤海地区 43 个地级市居民对所在城市居住环境的主观感受。 参考张文忠等人的《中国宜居城市研究报告》(张文 忠等, 2006)中的数据采集方法, 问卷中对居住环境 评价的问题设置为: “您对现有城市人居环境进行 评价”, 设置为 “非常满意 100 , 比较满意 80 ,一般 60 , 比较不满意 30 , 很不满意 0 ”。根据上文分析的 居住环境差异的形成原因,本文将居住环境细分为 城市安全、公共服务设施、自然环境、社会文化环 境、交通条件和环境健康六大要素,询问居民对所 在城市六项居住环境要素和整体居住环境的主观 感受。本次调研以常住居民为主,不包括短期停留 或旅游、出差人群。调查方式主要采用抽样调查, 具体采用分层抽样、等距随机抽样、交叉控制配额 (年龄、性别)抽样等多种抽样方法相结合的调查方 法, 目的是确保调查样本的代表性。调查范围以市 辖区范围为主。以城市规模为主要标准设定样本 数量, 按照直辖市 300 份、省会和副省级城市 250 份、其他城市根据规模大小各 200 或 150 份的标准 发放问卷,共发放问卷 7500 份, 回收有效问卷 6965 份, 有效率为 $93 \%$ 。通过对调查主体的性别、年龄、 城市分布等特征进行分析, 结果表明样本符合控制 要求, 合格问卷的数量和分布结构满足抽样设计和 研究要求。剔除本次核心变量未填写的样本, 共计 6601 份问卷用于分析。 43 个城市的样本分布从 83 份至 211 份不等(图 2), 平均每个城市收集到样本数 量为 153 份。用于本文的客观数据中(表 1 ), 城市市 辖区用地面积、人口、GDP、人均 GDP、在岗职工平 均工资、人口密度、第三产业比重、人均道路面积、 建成区绿化率取自《中国城市统计年鉴 2013 》, 人均 住房建筑面积、外来人口比重取自各城市 2010 年的 《第六次全国人口普查》, PM 2.5 暴露天数取自北京 城市实验室公布数据 ${ }^{1}$ 。

\section{2 研究方法}

(1) 多层线性模型

居住环境评价的差异缘于个体层级与城市层

(1)北京城市实验室收集了全国 190 个城市地面空气质量监测站点从 2013 年 4 月至 2014 年 4 月之间为期一年的日均 PM 2.5 浓度数据, 定义为 PM2.5 暴露天数。数据详见北京城市实验室网站:http://www.beijingcitylab.com/projects-1/13-pm2-5/。 
级, 要计算每个层级的差异需要采用基于数据分层 思想的多层线性模型。由于本文仅应用多层线性 模型计算城市层级可解释的居住环境评价差异的 方差比重, 因此构建如下多层线性空模型 ${ }^{2}$ :

$$
\begin{gathered}
y_{i j}=\beta_{0 i j} \text { cons } \\
\beta_{0 i j}=\beta_{0}+\mu_{j}+\varepsilon_{i j} \\
u_{j} \sim N\left(0, \sigma_{u}^{2}\right), \varepsilon_{i j} \sim N\left(0, \sigma_{\mathrm{e}}^{2}\right), \operatorname{cov}\left(u_{j}, \varepsilon_{i j}\right)=0
\end{gathered}
$$

式中: $y_{i j}$ 表示居民对所在城市的居住环境评价结果， $i$ 和 $j$ 分别表示居民和城市两个层级; $\beta_{0}$ 和 cons 分别

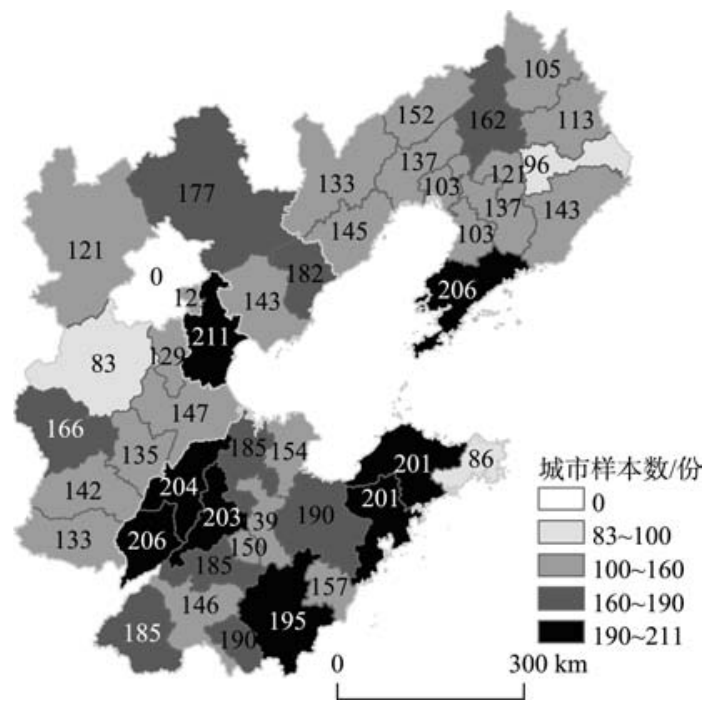

图 2 研究范围与调研样本分布图

Fig.2 Research area and distribution of the survey samples
表示常数项的固定效应系数和固定效应; $u_{j}$ 为城市 层级的随机效应, 服从均值为 0 , 方差为 $\sigma_{u}{ }^{2}$ 的正态分 布; $\varepsilon_{j j}$ 为居民的随机效应, 服从均值为 0 , 方差为 $\sigma_{\varepsilon}{ }^{2}$ 的正态分布; $u_{j}$ 和 $\varepsilon_{i j}$ 被假定为相互独立。与单层回 归模型相比,多层模型最大的不同之处在于回归模 型的截距和斜率都不再是一个固定常数, 而是随机 变量。例如, 原来单层模型的截距项 $\beta_{0}$ 变为多层模 型中的 $\beta_{0 i j}, \beta_{0 i j}$ 由三部分构成: 固定效应 $\beta_{0}$ 、城市层级 随机效应 $u_{j}$ 、居民层级随机效应 $\varepsilon_{i j}$ 。运用该模型, 我 们可以估计居住环境评价在城市层级的空间分异 程度, $\sigma_{u}^{2} /\left(\sigma_{u}^{2}+\sigma_{\mathrm{e}}^{2}\right)$ 表示居住环境评价在城市层级的 空间差异对评价结果总体差异的解释程度。有关多 层线性模型的详细解释见 Goldstein(2003)。

(2) 多元线性回归模型

上文提到,城市自身的属性特征可以解释城市 居住环境评价的差异，下文将验证城市特征对基于 居民主观感受的居住环境评价的影响。关于城市 特征对居民主观评价的影响分析采用多元线性回 归模型,模型设定如下:

城市居住环境评价 $=\beta_{0}$ cons $+\beta_{i}$ 城市特征 ${ }_{i}+\varepsilon(2)$

与式(1)表达的基于个体的多层线性模型不同， 式(2)表达的是基于城市的回归模型,式中因变量为 基于主观满意度评价的城市居住环境得分, 自变量 为城市特征。需要说明的是, 受数据的限制, 本文 选择的变量无法囊括图 1 反映的所有影响因素,最

\begin{tabular}{|c|c|c|c|}
\hline 变量 & 说明 & 均值(标准差) & 数据来源 \\
\hline 居住环境评价 & 居住环境满意度评价得分均值 & $68.5(7.2)$ & 调研问卷 \\
\hline 面积 & 用地面积 $/ \mathrm{km}^{2}$ & $1530.3(1387.3)$ & 城市统计年鉴 2013 \\
\hline 人口 & 年末人口/万人 & $162.1(145.0)$ & 城市统计年鉴2013 \\
\hline GDP & 地区生产总值/万元 & $1432.4(20637.0)$ & 城市统计年鉴 2013 \\
\hline 职工工资 & 在岗职工平均工资/(元/人) & 43991.0(7186.2) & 城市统计年鉴2013 \\
\hline 人均 GDP & 人均地区生产总值/(元/人) & $68870.0(33854.2)$ & 城市统计年鉴2013 \\
\hline 人口密度 & 人口密度/(人/km²) & $1643.9(1603.3)$ & 城市统计年鉴 2013 \\
\hline 三产比重 & 第三产业比重/\% & $42.3(9.5)$ & 城市统计年鉴 2013 \\
\hline 道路面积 & 人均城市道路面积 $/ \mathrm{m}^{2}$ & $14.8(5.7)$ & 城市统计年鉴 2013 \\
\hline 住房面积 & 人均住房建筑面积/(m²/人) & 29.6(4.6) & 第六次全国人口普查 \\
\hline 临海性 & 是否为临海城市 $/$ 是 $=1$, 否 $=0$ & $0.4(0.5)$ & \\
\hline 绿化率 & 建成区绿化覆盖率/\% & $40.9(5.4)$ & 城市统计年鉴 2013 \\
\hline 外来人口 & 外来人口比重 $/ \%$ & $53.0(15.0)$ & 第六次全国人口普查 \\
\hline PM2.5 暴露 & 2013.4-2014.4 间 PM2.5 暴露天数 & $147.0(70.5)$ & 北京城市实验室 \\
\hline
\end{tabular}

表 1 研究数据基础统计

Tab.1 Description of data and variables

(2)空模型即仅引入常数项固定效应和随机效应的模型, 不引人其他解释变量。 
终选取的城市特征变量包括: 反映城市规模与经济 发展水平的用地面积、总人口、GDP、在岗职工平均 工资、人均 GDP、人口密度、第三产业比重、人均道 路面积、人均住房建筑面积、绿化率; 反映自然环境 的临海性, 反映社会文化因素的外来人口比重, 反 映环境污染情况的雾霻暴露天数。

\section{4 实证分析结果}

\section{1 城市之间的居住环境主观评价结果差异}

4.1.1 城市之间总体差异

首先, 为了解环渤海地区城市尺度主观评价的 居住环境是否存在差异以及有多少差异, 采用多层 线性模型方法分别提取城市和居民层级可解释的 主观评价方差比重。这里应用MLwiN2.32进行多 层线性模型的模拟,结果发现,城市与居民层级的
方差比重分别为 $19.3 \%$ 和 $80.7 \%$, 可见城市尺度的 主观评价有非常显著的差异, 即在不同的城市之 间,居民对居住环境的评价表现出非常不一致的特 征。此外,表 2 分别给出最好和最差城市的居住环 境评价预测值, 最好城市满意度得分比最差城市高 出 28.1 。

图 3 显示了环渤海 43 个城市居住环境主观评 价的空间投射。威海市、盘锦市、营口市、潍坊市是 评价得分最高的 4 个城市,保定市、东营市、衡水市、 石家庄市是得分最低的 4 个城市。天津市的评价得

表 2 居住环境评价的多层线性模型方差估计结果

Tab.2 Variance estimates for the multilevel model of living environment evaluation

\begin{tabular}{cccc}
\hline $\begin{array}{c}\text { 个体层级方差 } \\
\text { (总方差中比重) }\end{array}$ & $\begin{array}{c}\text { 城市层级方差 } \\
\text { (总方差中比重) }\end{array}$ & 最好城市 & 最差城市 \\
\hline $217.5(80.7 \%)$ & $52.1(19.3 \%)$ & 83.2 & 55.1 \\
\hline
\end{tabular}
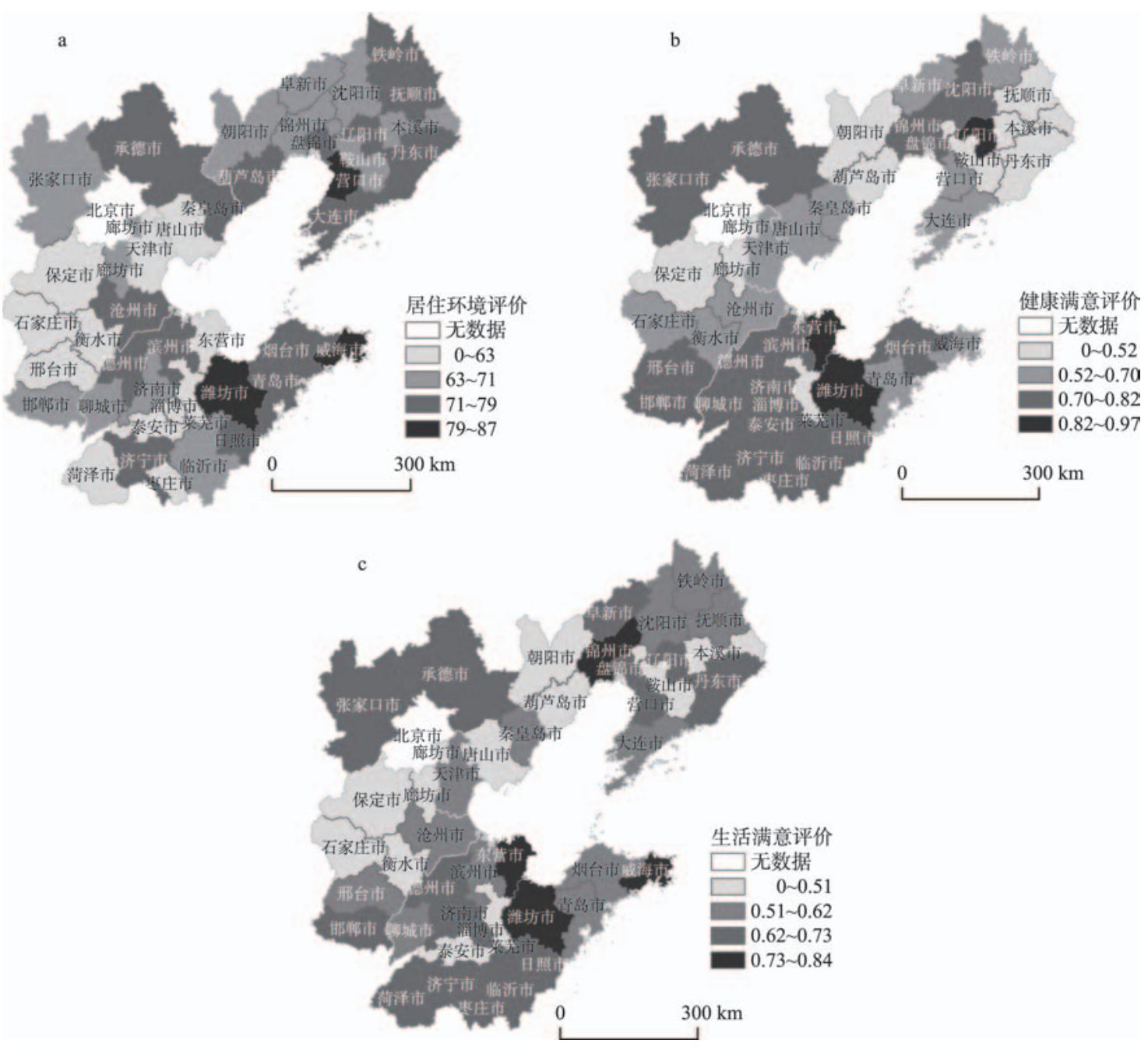

图 3 环渤海地区居住环境及满意度主观评价示意图

Fig.3 Subjective evaluation of living environment and well-being in the Bohai Rim area 
分为 60.3 , 排名第 39 位; 河北省 11 个地级市的评价 结果均值为 64.2 , 明显低于其他两个省份。此外, 环渤海地区评价最低的几个城市主要位于河北省; 辽宁省的城市评价结果均较高, 14 个地级市的评价 结果均值为 72.1 ; 山东省 17 个地级市的评价结果差 别最明显, 既有第一名的威海市, 也有倒数第二名 的东营市,位于中部沿东北一西南走向分布的城市 得分最低。不难看出, 评价最高的几个城市均位于 沿海地带, 尤其是威海市、淮坊市和营口市, 足见临 海性对城市宜居性的重要影响。

居住环境的优劣是影响居民生活质量的重要 因素(Brereton et al, 2008)。进一步将城市居民的身 体健康状况和生活满意度评价投射到空间上, 分别 以每个城市内选择身体非常健康或比较健康、对当 下生活非常满意或比较满意的人数比例来表征城 市居民的健康性和生活满意度评价。河北省的健 康满意度和生活满意度评价结果与居住环境评价 结果的空间投射比较相似, 表现为承德市与张家口 市居民的各项满意度得分均较高, 其次是位于边界 的城市。明显不同的是山东省, 虽然山东省西南部 多数城市居民的居住环境评价并不高, 但这些城市 的健康满意度较高, 生活满意度的评价结果与居住 环境评价结果的空间表现比较类似。辽宁省的居住 环境评价虽然整体较高, 但多数城市的居民健康满 意度评价反而较低。总的来说, 居住环境评价较高 的城市其居民对自身健康状况和生活满意度的评 价也较高, 表明了居住环境对居民生活的重要影响。

\subsection{2 分要素评价结果差异}

图 4 显示了 43 个城市居住环境六大要素的满 意度评价结果。整体而言, 环境健康性是六大要素 中居民最不满意度的要素, 除了威海市、丹东市、营 口市、辽阳市、承德市、张家口市以外, 其他城市的 环境健康性评价在六项要素中得分均较低。同样,
除秦皇岛市、沧州市、大连市及山东省个别城市以 外,自然环境的整体评价得分也较低。公共服务设 施在大部分城市的得分均较高, 但是在东营和菏泽 两市的得分相对较差。就城市安全性而言, 保定市 和泰安市的安全性较差, 而且这两个城市的交通条 件满意度评价也最差。对交通条件评价较高的城 市包括营口市、潍坊市、盘锦市和威海市, 而且这 4 个城市的社会文化环境评价较高。对社会文化环 境评价最低的几个城市包括保定市、菏泽市与莱芜 市, 评价最高的几个城市分别为承德市、营口市、淮 坊市和威海市。

此外, 天津市及河北省的石家庄市、唐山市、邯 部市、邢台市、保定市、衡水市以及山东省的淄博市 和辽宁省的沈阳市的城市六项居住环境要素评价 得分差别明显,这些城市也是总体评价得分较低的 几个城市; 而几个得分较高的城市, 其居住环境六 项要素的得分差别并不明显。说明城市居住环境 评价存在 “短板效应”, 当一项居住环境要素评价较 低时,会直接拉低城市的整体评价得分。

\subsection{3 不同类型城市的评价结果差异}

进一步按照城市的人口、用地、密度、GDP及是 否为临海或资源/工业城市进行划分,对比分析不同 类型城市的评价结果(表 3)。临海城市的居民对所 在城市的居住环境评价(72.5)高于非临海的城市 (65.9); 同样,非资源型或工业城市的居民满意度 (70.1)高于资源型或工业城市(66.9)。人口规模最 小的城市居民满意度(均值 72.5)明显高于人口规模 最大的城市 (均值 65.3); 同样, 人口密度较小的一类 (69.6) 和二类城市(70.4)居民满意度要高于人口密 度较大的三类(68.5)和四类城市(65.8); 用地面积为 二类的城市满意度最高 (74.0), 面积最小的一类城 市得分最低(65.4);GDP 较低的前三类城市满意度 明显高于较高的第四类城市(65.1)。

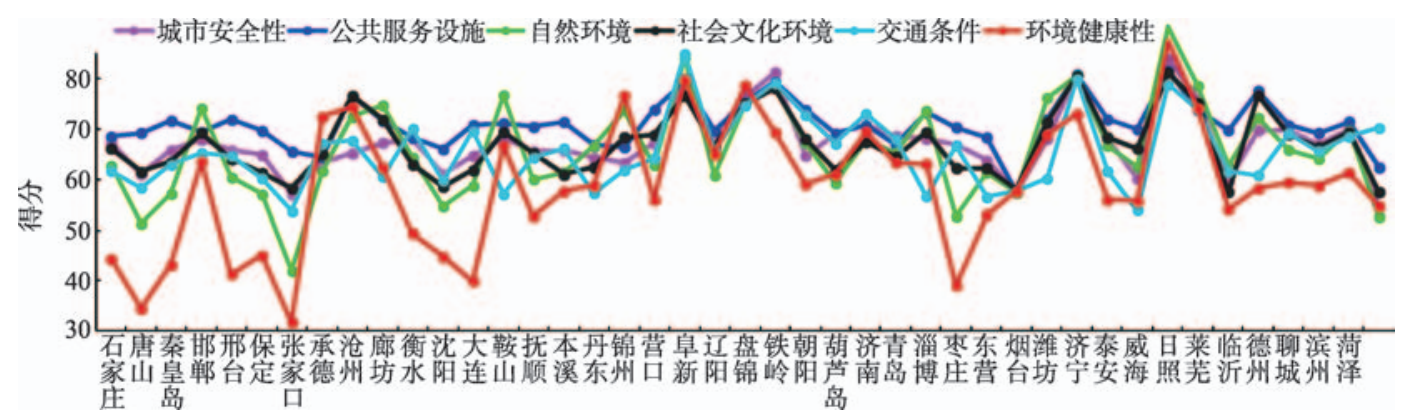

图 4 居住环境六大要素评价示意图

Fig.4 Subjective evaluation of the six elements of living environment 


\section{2 城市特征对居民主观评价结果的影响}

本节将重点分析城市自身的特征是如何影响 居民对城市的主观评价。表 4 给出基于多元回归分 析的城市特征对居住环境评价的影响分析。由于 城市面积、人口、GDP 及职工工资之间存在显著的 相关性, 因此将这 4 个变量分别引人模型。除临海 性以外,所有变量在进人模型前首先经过标准化处 理, 因此我们可通过比较变量系数的大小来分析不 同指标对居民主观评价的影响。

首先, 从反映城市规模的面积和人口来看, 在 控制其他变量之后, 城市面积对主观评价的影响显 著为负。说明随着城市规模的扩张, 居民对城市居

表3 分类别城市的居住环境评价结果

Tab.3 Evaluation of living environment in different types of cities

\begin{tabular}{|c|c|c|c|c|c|}
\hline 类别划分 & 分类 & 评价得分 & 类别划分 & 分类 & 评价得分 \\
\hline \multirow[t]{2}{*}{ 临海性 } & 否 & 65.9 & \multirow{2}{*}{$\begin{array}{l}\text { 资源/工业 } \\
\text { 城市 }\end{array}$} & 否 & 70.1 \\
\hline & 是 & 72.5 & & 是 & 66.9 \\
\hline \multirow[t]{4}{*}{ 人口规模 } & 一 & 72.5 & \multirow[t]{4}{*}{ 用地面积 } & 一 & 65.4 \\
\hline & 二 & 67.4 & & 二 & 74.0 \\
\hline & 三 & 68.6 & & 三 & 67.6 \\
\hline & 四 & 65.3 & & 四 & 67.0 \\
\hline \multirow[t]{4}{*}{ 人口密度 } & 一 & 69.6 & \multirow[t]{4}{*}{ GDP } & 一 & 68.4 \\
\hline & 二 & 70.4 & & 二 & 70.2 \\
\hline & 三 & 68.5 & & 三 & 70.1 \\
\hline & 四 & 65.8 & & 四 & 65.1 \\
\hline
\end{tabular}

住环境的评价下降。同样城市人口也表现出人口 越多,居住环境的评价越低, 暗示生活在小城市的 居民相比大城市居民更加满意所居城市的居住环 境品质。从反映城市经济发展水平的 GDP、人均 GDP 和职工平均工资来看, GDP 对居住满意度有非 常显著的负面影响,而人均 GDP 仅在模型 II 中显示 出 $90 \%$ 的显著负面影响,说明高经济发展水平并非 对应高居住环境评价。非常有意义的是,职工平均 工资对居住环境评价也有显著的负面影响,这或许 与上文提及的大城市工资水平高而居住环境品质 较差有关系, 通常大城市居民的收人水平相对要高 于中等城市, 而中等城市又高于小城市, 但是居住 环境质量尤其是自然环境指标却表现出相反的特 征。人口密度反映城市的发展密度, 在人口密度高 的城市, 居民的满意度较低, 可能的原因是高人口 密度的城市公共服务设施、住房等资源更为紧缺, 居民可享受到的高品质生活有限, 因而对居住环境 满意度评价较低。从城市的产业发展特征来看, 本 文选用的第三产业比重并没有对居民的居住环境 评价有显著的影响。从城市建设来看, 模型 III 中, 人均道路面积对居住环境评价有显著的正面影响, 即人均道路面积更多的城市，居民的满意度更高。 人均住房建筑面积对满意度的影响为负, 暗示住房 面积大并不对应更高的居住环境评价,由于居住环 境评价更多是居民对所在城市各要素的评价,而不

表4 居住环境主观评价的影响因素分析(1)

Tab.4 Result of influencing factor analysis of subjective evaluation of living environment (1)

\begin{tabular}{|c|c|c|c|c|}
\hline 变量 & 模型 I & 模型 II & 模型 III & 模型 IV \\
\hline 面积 & $-0.369^{* *}(0.146)$ & & & \\
\hline 人口 & & $-0.291^{* *}(0.140)$ & & \\
\hline GDP & & & $-0.336^{* *}(0.153)$ & \\
\hline 职工工资 & & & & $-0.331^{* *}(0.148)$ \\
\hline 人均 GDP & $-0.292(0.180)$ & $-0.336^{*}(0.182)$ & $-0.269(0.193)$ & \\
\hline 人口密度 & $-0.564^{* * *}(0.142)$ & $-0.442^{* * *}(0.135)$ & $-0.447^{* * *}(0.135)$ & $-0.332^{* *}(0.144)$ \\
\hline 三产比重 & $0.107(0.141)$ & $0.132(0.152)$ & $0.144(0.152)$ & $0.091(0.147)$ \\
\hline 道路面积 & $0.238(0.146)$ & $0.240(0.152)$ & $0.271^{*}(0.15)$ & $0.172(0.159)$ \\
\hline 住房面积 & $-0.224^{*}(0.129)$ & $-0.263^{*}(0.132)$ & $-0.291^{* *}(0.132)$ & $-0.164(0.142)$ \\
\hline 临海性 & $1.068^{* * * *}(0.280)$ & $1.053^{* * * *}(0.288)$ & $1.103^{* * *}(0.285)$ & $0.920^{* * *}(0.289)$ \\
\hline 绿化率 & $0.097(0.120)$ & $0.093(0.123)$ & $0.081(0.122)$ & $0.153(0.135)$ \\
\hline 外来人口 & $0.125(0.161)$ & $0.151(0.164)$ & $0.111(0.167)$ & $0.122(0.167)$ \\
\hline 常数项 & $-0.422^{* * *}(0.159)$ & $-0.416^{* *}(0.164)$ & $-0.436^{* *}(0.162)$ & $-0.364^{* *}(0.171)$ \\
\hline 调整 $R^{2}$ & 0.437 & 0.406 & 0.414 & 0.300 \\
\hline
\end{tabular}

注: ***表示在 0.01 水平下显著; $* *$ 表示在 0.05 水平下显著; $*$ 表示在 0.1 水平下显著。 
是局限于对个体自身住房特征的评价, 个体即便对 应更优越的自家住房特征,也并不意味着居民对整 个城市的居住环境表示满意。从反映城市自然环 境的临海性和建成区绿化率来看, 临海性对居住环 境评价有显著的正面影响, 说明临海城市的居住环 境品质明显优于内陆城市, 不仅有丰富且易获取的 海洋资源, 自然风光也较内陆城市更为优越。建成 区绿化率对居住环境评价没有显著的影响, 同样, 外来人口也未有显著影响。

2013 年以来, 雾霧污染进人公众视线, 尤其是 北方地区进人冬季就成为全国的雾䨪重灾区。本 次调研中发现, 居民普遍反映越来越严重的雾霧污 染是制约生活质量提升的关键因素, 甚至有居民表 示为 “躲避”雾䨪情愿迁居他地。虽然雾䨪仅仅是 人居环境五大系统之一一自然系统中的一项内 容, 但不得不承认, 近年来严重的雾䨪污染问题已 经上升为影响环渤海地区城市居住环境质量的最 重要因素。基于此, 接下来的分析中将雾䨪作为一 项特殊因素单独加人模型。本文采用环渤海城市 在 2013 年 4 月至 2014 年 4 月之间的 PM2.5 暴露天 数作为反映雾䨪污染程度的指标。可以看到, PM2.5 暴露天数对居民的居住环境评价有显著的 负面影响, 即城市的雾䨪污染越严重, 居民感受到 的居住环境质量越差。在可比较的变量(除临海性 以外)中, PM 2.5 暴露的系数最大, 说明雾䨪污染是
影响居民主观评价最重要的因素。此外,引人雾䨪 污染之后, 反映城市规模和经济发展水平的面积、 人口、GDP不再显著, 人口密度也仅在模型 IV 中显 著, 说明在控制雾䨪污染指标之后, 其他指标的影 响将有所下降,进一步证明了空气质量对居住环境 评价的重要性。虽然控制了雾䨪指标, 表 5 的 4 个 模型中临海性依然有非常显著的正面影响。对于 城市而言, 临海不仅仅是海洋资源的可获取性, 更 重要是污染气体易于扩散,在当前中国城市雾霧污 染严重的时期, 临海性对宜居性的重要性程度比以 往更加凸显。

\section{5 结论与讨论}

城市作为人类聚居的基本形态之一, 是人对自 然改造最强烈的地区，城市居住环境呈现出的人与 自然的矛盾在全球地域范围内最为突出, 因此城市 是居住环境研究的主要聚焦点,研究城市尺度的居 住环境问题可为中国新型城镇化和生态文明建设 提供科学依据。本文在环渤海地区大样本调查问 卷基础上,综合运用多层线性模型、GIS 空间分析和 多元线性回归分析模型,对研究区域内 43 个城市基 于居民主观感受的居住环境进行评价,并探讨城市 客观特征对主观评价结果的影响, 主要得到以下几 点结论与启示:

表 5 居住环境主观评价的影响因素分析(2)

Tab.5 Result of influencing factor analysis of subjective evaluation of living environment (2)

\begin{tabular}{|c|c|c|c|c|}
\hline 变量 & 模型 I & 模型 II & 模型III & 模型 IV \\
\hline 面积 & $-0.233(0.147)$ & & & \\
\hline 人口 & & $-0.146(0.142)$ & & \\
\hline GDP & & & $-0.187(0.154)$ & \\
\hline 职工工资 & & & & $-0.172^{* *}(0.145)$ \\
\hline 人均 GDP & $-0.277(0.168)$ & $-0.319^{*}(0.169)$ & $-0.274(0.179)$ & \\
\hline 人口密度 & $-0.279(0.177)$ & $-0.183(0.162)$ & $-0.191(0.161)$ & $-0.065^{* *}(0.161)$ \\
\hline 三产比重 & $0.072(0.132)$ & $0.071(0.143)$ & $0.084(0.143)$ & $0.072(0.134)$ \\
\hline 临海性 & $0.785^{* * * 4}(0.286)$ & $0.763^{* * *}(0.291)$ & $0.792^{* *}(0.292)$ & $0.537^{*}(0.294)$ \\
\hline 道路面积 & $0.328^{* *}(0.143)$ & $0.339^{* *}(0.146)$ & $0.353^{s *}(0.143)$ & $0.289^{*}(0.150)$ \\
\hline 绿化率 & $0.085(0.112)$ & $0.082(0.114)$ & $0.075(0.113)$ & $0.116(0.123)$ \\
\hline 住房面积 & $0.032(0.160)$ & $0.028(0.168)$ & $0.006(0.170)$ & $0.144(0.167)$ \\
\hline 外来人口 & $-0.014(0.160)$ & $-0.002(0.164)$ & $-0.024(0.164)$ & $-0.093(0.169)$ \\
\hline PM2.5 暴露 & $-0.495^{* *}(0.204)$ & $-0.53^{* *}(0.210)$ & $-0.521^{* *}(0.207)$ & $-0.620^{* * * *}(0.217)$ \\
\hline 常数项 & $-0.31^{*}(0.155)$ & $-0.302^{*}(0.159)$ & $-0.313^{* * *}(0.158)$ & $-0.212(0.164)$ \\
\hline 调整 $R^{2}$ & 0.510 & 0.489 & 0.495 & 0.423 \\
\hline
\end{tabular}

注: ***表示在 0.01 水平下显著; **表示在 0.05 水平下显著; *表示在 0.1 水平下显著。 
(1) 环渤海 43 个城市的居民环境评价有显著的 差异。辽宁省城市的评价结果整体较优, 河北省城 市的评价结果整体较差。河北省是全国重要的钢 铁产量大省, 煤炭消费量大, 能源结构不合理, 加之 部分城市受特殊地形的影响, 工业生产排放的污染 气体扩散难度大, 导致河北省大部分城市雾霳污染 非常严重, 这也是引起居民对河北省城市居住环境 最不满意的直接原因。

(2) 居住环境评价存在 “短板效应”。环境健康 性是多数居住环境评价得分较低城市的共同短 板。环境健康性得分较低主要受近两年不断加剧 的雾䨪污染的影响, 本文的模型分析也证实了雾䨪 污染对城市居住环境评价的负面影响最大。除环 境健康性以外, 多数城市居住环境的六大要素中自 然环境的得分也较低,公共服务设施得分较高。

(3) 城市特征影响居住环境评价, 城市规模越 大、人口密度越高、经济发展水平越高, 居住环境的 满意度越低, 中小城市的居住环境满意度普遍高于 大城市。从个体视角来看, 居民要在收人高而居住 环境差的大城市和收人低而居住环境优的小城市 之间进行权衡, 进而作出居住迁移决策。从城市发 展视角来看, 个体的居住迁移, 尤其是高素质人才 的居住迁移对城市发展有至关重要的影响, 如何改 善城市居住环境品质, 吸引并留住高端人才, 是城 市居住环境升级改造的重要内容。

(4) 临海城市的居民对所在城市的满意度评价 更高。当前, 城市的临海性已经不仅是海洋资源与 海上通道的可获取性, 更重要是在环境健康性上表 现出的优势地位。然而, 唐山、天津等临海城市的 满意度仍然很低, 这与城市严重的雾䨪污染密切相 关, 可见在城市居住环境的可提升要素中, 治理雾 皬是当前最迫切的任务。

虽然基于主观感受评价的居住环境会受到个 体差异的影响, 呈现出评价结果 “因人而异” 的现 象, 不过本文使用多层线性模型的分析结果指出, 城市层级方差可以解释的居住环境评价结果差异 达到 $20 \%$, 表明使用主观数据研究城市尺度的居住 环境差异时, 尺度效应不容忽视。这一结论也为今 后的同类研究提供了一个值得借鉴的思路与方法, 即运用数据分层的思想解决主观评价中的尺度变 异问题。

本文仅仅介绍了环渤海地区城市的居住环境 差异, 并没有对居住环境差异的形成原因及内在机
制进行更深人的解析, 未来需要进一步研究人类活 动对城市居住环境质量变化的作用机制, 尤其是分 析工业化、城镇化过程和方式对居住环境质量的影 响。此外, 本文的研究范围限制在环渤海 43 个城 市, 而中国地域范围广阔, 全国尺度的居住环境差 异需要引起更多的重视, 这也将是我们今后的研究 方向。

\section{参考文献(References)}

谌丽, 张文忠, 党云晓, 等. 2012. 北京市低收人人群的居住 空间分布、演变与聚居类型研究 [J]. 地理研究, 31(4): 720-732. [Chen L, Zhang W Z, Dang Y X, et al. 2012. The spatial distribution, transition and residential pattern of low-income residents in Beijing[J]. Geographical Research, 31(4): 720-732.]

谌丽, 张文忠, 李业锦. 2008. 大连居民的城市宜居性评价研 究[J]. 地理学报, 63(10): 1022-1032. [Chen L, Zhang W Z, Li Y J. 2008. Urban residential suitability evaluation of Dalian's residents[J]. Acta Geographica Sinica, 63 (10): 1022-1032.]

党云晓, 张文忠, 余建辉, 等. 2014. 北京居民主观幸福感评 价及影响因素研究 [J]. 地理科学进展, 33(10): 13121321. [Dang Y X, Zhang W Z, Yu J H, et al. 2014. Residents' subjective well- being and influencing factors in Beijing[J]. Progress in Geography, 33(10): 1312-1321.] 胡最, 邓美容, 刘沛林, 等. 2011. 基于 GIS 的衡阳人居适宜度 评价 [J]. 热带地理, 31(2): 211-215. [Hu Z, Deng M R, Liu P L, et al. 2011. Niche suitable assessment for human settlement in Hengyang based on GIS[J]. Tropical Geography, 31(2): 211-215.]

李王鸣, 叶信岳, 孙于. 1999. 城市人居环境评价: 以杭州城 市为例 $[J]$. 经济地理, 19(2): 38-43. [Li W M, Ye X Y, Sun Y. 1999. The assessment of urban human Settlements: A case study of Hangzhou[J]. Economic Geography, 19(2): 38-43.]

李雪铭, 李明. 2008. 基于体现人自我实现需要的中国主要 城市人居环境评价分析 [J]. 地理科学, 28(6): 742-747. [Li X M, Li M. 2008. Evaluation and analysis of the major urban human settlements based on embodying self-realization needs in China[J]. Scientia Geographica Sinica, 28(6): 742-747.]

李雪铭, 张春花, 张馨, 等. 2004. 城市化与城市人居环境关 系的定量研究: 以大连市为例 $[\mathrm{J}]$. 中国人口・资源与环 境, 14(1): 91-96. [Li X M, Zhang C H, Zhang X, et al. 2004. Quantitatine research on urbanization and environment for human settlements: Take Dalian as an example 
[J]. China Population, Resources and Environment, 14 (1): 91-96.]

李业锦. 2009. 城市宜居性的空间分异机制研究: 以北京市

为例 [D]. 北京: 中国科学院大学. [Li Y J. 2009. Study on spatial differentiation mechanism of urban livability: A case of Beijing city[D]. Beijing, China: University of Chinese Academy of Sciences.]

浅见泰司. 2006. 居住环境: 评价方法与理论[M]. 高晓路, 张 文忠, 李旭, 等, 译. 北京: 清华大学出版社. [Asami Y. 2006. Juzhu huanjing: Pingjia fangfa yu lilun[M]. Gao X L, Zhang W Z, Li X, et al, Trans. Beijing, China: Tsinghua University Press.]

吴良镛. 2001. 人居环境科学导论 [M]. 北京: 中国建筑工业 出版社. [Wu L Y. 2001. Introduction to sciences of human settlements[M]. Beijing, China: China Architecture and Building Press. ]

姚士谋, 陆大道, 王聪, 等. 2011. 中国城镇化需要综合性的 科学思维: 探索适应中国国情的城镇化方式 $[\mathrm{J}]$. 地理研 究, 30(11): 1947-1955. [Yao S M, Lu D D, Wang C, et al. 2011. Urbanization in China needs comprehensive scientific thinking: exploration of the urbanization mode adapted to the special situation of China[J]. Geographical Research, 30(11): 1947-1955.]

湛东升, 张文忠, 党云晓, 等. 2015. 中国城市化发展的人居 环境支撑条件分析 [J]. 人文地理, 30(1): 98-104. [Zhan D S, Zhang W Z, Dang Y X, et al. 2015. An analysis of supporting conditions of living environment for urbanization development in China[J]. Human Geography, 30(1): 98-104.]

张文忠, 谌丽, 杨翌朝. 2013. 人居环境演变研究进展 $[\mathrm{J}]$. 地 理科学进展, 32(5): 710-721. [Zhang W Z, Chen L, Yang Y Z. 2013. Progress in research on human settlement evolution[J]. Progress in Geography, 32(5): 710-721.]

张文忠, 尹卫红, 张锦秋, 等. 2006. 中国宜居城市研究报 告 $[\mathrm{M}$ ]. 北京: 社会科学文献出版社. [Zhang W Z, Yin W H, Zhang J Q, et al. 2006. A study of livable cities in China[M]. Beijing, China: Social Sciences Academic Press.]
张文忠, 余建辉, 李业锦, 等. 2015 . 人居环境与居民空间行 为 $[\mathrm{M}$ ]. 北京: 科学出版社. [Zhang W Z, Yu J H, Li Y J, et al. 2015. Human settlement and spatial behavior of residents[M]. Beijing, China: Science Press.]

Asami Y. 2001. Residential environment: methods and theory for evaluation[M]. Tokyo: University of Tokyo Press.

Beeson P E. 1991. Amenities and regional differences in returns to worker characteristics[J]. Journal of Urban Economics, 30(2): 224-241.

Brereton F, Clinch J P, Ferreira S. 2008. Happiness, geography and the environment[J]. Ecological Economics, 65(2): 386-396.

Clos J. 2011. Keynote speech in international symposium on sciences of human settlements[C]//Proceeding of $2011 \mathrm{In}$ ternational Symposium on Sciences of Human Settlements. Beijing, China: CAE.

Glaeser E L, Gottlieb J D. 2006. Urban resurgence and the consumer city[J]. Urban Studies, 43(8): 1275-1299.

Glaeser E L, Kolko J, Saize A. 2001. Consumer city[J]. Journal of Economic Geography, 1(1): 27-50.

Goldstein H. 2003. Multilevel statistical methods[M]. 3rd ed. London: Edward Arnold.

Mohit M A, Ibrahim M, Rashid Y R. 2010. Assessment of residential satisfaction in newly designed public low- cost housing in Kuala Lumpur, Malaysia[J]. Habitat International, 34(1): 18-27.

Roback J. 1982. Wages, rents, and the quality of life[J]. Journal of Political Economy, 90(6): 1257-1278.

Savageau D. 2007. Places rated almanac: the classic guide for finding your best places to live in America[M]. 7th ed. Washington, DC: Places Rated Books, LLC.

Talen E. 2006. Neighborhood-level social diversity: insights from Chicago[J]. Journal of the American Planning Association, 72(4): 431-446.

Torrens P M. 2006. Simulating sprawl[J]. Annals of the Association of American Geographers, 96(2): 248-275.

Ullman E L. 1954. Amenities as a factor in regional growth[J]. Geographical Review, 44(1): 119-132. 


\title{
Satisfaction evaluation of living environment and influencing factors in the Bohai Rim area
}

\author{
DANG Yunxiao ${ }^{1,2,3}$, YU Jianhui ${ }^{1,2^{*}}$, ZHANG Wenzhong $^{1,2}$, LI YeJin $^{4}$, \\ CHEN $\mathrm{Li}^{5}$, ZHAN Dongsheng ${ }^{1,2}$ \\ (1. Key Laboratory of Regional Sustainable Development Modeling, CAS, Beijing 100101, China; \\ 2. Institute of Geographic Sciences and Natural Resources Research, CAS, Beijing 100101, China; \\ 3. University of Chinese Academy of Sciences, Beijing 100049, China; \\ 4. College of Resource Environment and Tourism, Capital Normal University, Beijing 100048, China; \\ 5. College of Applied Arts and Science, Beijing Union University, Beijing 100191, China)
}

\begin{abstract}
In recent years, living environment of urban areas in China is attracting increasingly more attention of researchers and urban residents particularly due to the problems caused by rapid economic development. Meanwhile, improving living environment quality is becoming an important target of urban development for the Chinese government. In spite of the increasing number of studies on living environment at smaller scales, few studies have focused on the city scale. Based on a large survey conducted in 2014 in 43 cities of the Bohai Rim area, this study used multilevel modeling, GIS spatial analysis, and multiple linear regression to evaluate the living environment using residents' subjective perception as indicators, then analyzed the impact of city characteristics on the heterogeneity of the evaluation results. Several conclusions are drawn as follows: (1) There is a significant disparity of evaluation results between the 43 cities. The differences of influencing factors at the city level can explain $20 \%$ of the total satisfaction variance. The disparity of living environment quality of cities cannot be neglected in related research on the social, economic, and development issues of cities. Cities in Liaoning Province ranked the highest in the evaluation result while cities in Hebei Province were the worst due to the concentration of massive heavy industries, especially the steel industry. (2) Environment health is the main problem for all the cities that ranked low in the evaluation, which reaffirms that the key point to improve living environment quality is to control environment pollution. (3) Cities with larger land area and population and higher economic development levels normally ranked the lowest with regard to residents' satisfaction. Satisfaction on living environment is higher in small and medium-sized cities as compared to large cities. Residents living in coastal cities are more satisfied than inland cities. (4) At present, smog control and reduction is key to improving the quality of living environment in the Bohai Rim area.
\end{abstract}

Key words: living environment; satisfaction evaluation; influencing factors; Bohai Rim area 